\title{
Correlation Between Regional Competitiveness and Smart Regions
}

\author{
Adrian Petre $^{1 *}$, Marta Christina Suciu ${ }^{2}$ \\ ${ }^{1}$ The Bucharest University of Economic Studies, 6 Piata Romana, $1^{\text {st }}$ District, Bucharest, 010374 \\ Romania. \\ e-mail: adrian.petre21@gmail.com \\ 2 The Bucharest University of Economic Studies, 6 Piata Romana, $1^{\text {st }}$ District, Bucharest, 010374 \\ Romania. \\ e-mail: mcsuciu50@gmail.com
}

DOI: 10.51865/EITC.2021.04.07

\begin{abstract}
This scientific article represents an empirical research on the smart and sustainable development of Romania after the accession to the European Union. The main objective is to determine the current state of smart development of the four macro-regions of our country and to identify possible solutions for improving the performance and reducing the gaps. The research methodology applied in this case is based on critical comparative analysis, and statistical data. The results from the first part of the research shows, on the one hand, that between the macro-regions of the country there are gaps in terms of smart and sustainable development, and the highest performances are registered at the level of Macroregion three. On the other hand, the results show large gaps with Austria (performer in the smart development) with most of the dimensions characteristic of the smart regions / cities considered by us in this research. The results of the second part of the research demonstrates that the level of competitiveness has a decisive role in supporting the process of smart development and reducing gaps at national and international level, and stimulating innovation is essential for achieving the goal of smart, sustainable and inclusive long-term development.
\end{abstract}

Keywords: smart development; sustainability; competitiveness; innovation; Romania.

JEL Classification: O30; R13; R58.

\section{Introduction}

The United Nations estimates that between 2015 and 2050 the world's population will increase by $32 \%$, while the urban population will increase by $63 \%$, from 3.9 billion inhabitants to 6.3 billion inhabitants. This exponential growth of the urban population determines an increase in the degree of complexity in terms of managing urban spaces and their resources so that a high standard of living can be ensured for citizens.

\footnotetext{
${ }^{*}$ Corresponding author
} 
Thus, there is a need to identify innovative solutions to respond promptly, efficiently and sustainably to these challenges, and the main solution is the development and use of information and communication technologies (ICT) for a more efficient and intelligent use of resources, resulting in cost and energy savings, higher quality services, and greater protection for the environment.

In this way, smart cities or smart regions are developed, which use advanced digital technologies in order to generate a large amount of data and information about people, environment, economy, infrastructure, culture and urban life that are used to achieve strategic objectives on increasing the quality of life.

Given this aspects, the main objective of this scientific paper is to analyze the stage of smart development of the four macroregions of Romania, (Macroregion 1 - M1, Macroregion 2 - M2, Macroregion 3 - M3 and Macroregion 4 - M4) and to identify potential optimal solutions for smart, sustainable and inclusive long-term development and for reducing the disparities.

We consider that this analysis is even more important because it is representative even for the most important cities in the four macroregions of Romania and it is addressed both to researchers in this field and also to decision makers.

For the first part of the research we will select a series of indicators that characterize the dimensions of smart cities and we will test them at the level of the four macroregions of the country and then compared to a best practice at European level. For the second part of the research we will test the opportunity of smart and sustainable development and gap reduction through competitiveness, based on the general hypothesis that smart cities are developing in competitive areas.

This general hypothesis will be tested through 2 sub-hypotheses:

1. There is a positive and strong relationship between innovation and the position of countries in the competitiveness ranking;

2. There is a positive and strong relationship between the position of countries in the competitiveness ranking and the position of cities in the smart cities ranking.

Within this approach we are facing a number of limitations in terms of the availability of official statistical data for the regional level, but we believe that our research can be a solid foundation for future researches in this area.

\section{Brief Literature Review}

Our approach starts from the critical comparative analysis of some of the most representative scientific works in the field, which analyzes the sustainable and inclusive development of smart regions / cities.

Currently, urban areas are facing an increase in population density, which implies a greater allocation of resources for utilities, transport, construction, health, environmental protection and so on, generally speaking for an increase in the standard of living of citizens and economic prosperity.

According to most scientific studies in this field, the best solution to meet these challenges is the smart development of these areas through the smart solutions offered especially by highly qualified human capital and information and communication technologies (ICT), which are in continuous progress, they also inspiring the notion of "smart city".

(Apanaviciene et al., 2020) describe Smart Cyber-Physical Systems (CPS) automation with decentralized control and the Internet of Things (IoT), which enable advanced networking, as the foundation of smart cities, with physical and virtual identities, through which smart sensors 
measures, collects and stores real-time data that is instantly distributed via Internet networks, thus creating a permanent circuit of information between a large and varied number of systems and devices.

At the same time, (Lom et al., 2016) considers that two other fundamental elements of smart cities are Internet of Services (IoS) and Internet of Energy (IoE), systems that allow the efficient use of natural resources, public services, buildings and data.

Further, (Guo et al., 2017) states that the smart city represents an urban development that is mainly based on the broader and efficient integration of information and communication technologies in the management of local resources, while (Barney and Clark, 2007) say that the design and use of complex strategies to improve the efficiency and effectiveness of these resources is an important source in obtaining sustainable competitive advantages.

(Bakici et al., 2013) states that the smart city includes a multitude of advanced digital technologies that make connections between people, information and elements of cities in order to create a more sustainable, ecological and innovative environment, and that contributes to increase the life quality of its inhabitants.

According to (Romanelli, 2021) smart cities and smart communities contribute fundamentally to the development of urban smartness, aimed at urban sustainability and promote continuous innovation and knowledge creation.

In the current health context, (Fayomi and Sani, 2021) highlights the fact that the development of smart cities contributes significantly to the transition process on how to carry out the professional activity of citizens, allowing them to work remotely, thus generating benefits both for employees as well as for organizations.

On the other hand, (Florida, 2005) argues that citizens are a key element of smart cities, because only through their interaction such a city can be developed. The author considers that the smart population is the engine of the smart city development, and therefore the strategies must focus on the continuous development of smart human capital.

The same thing is emphasized by (Ortiz-Fournier et al. 2010), which describes the smart city based on the smart citizens and the connections that are established between them.

On these issues, (Szabo and Herman, 2014) and (World Bank, 2019) point out that human capital and the level of adoption of advanced technologies are in a positive correlation.

Recent scientific work in this area, such as (Kummitha and Crutzen, 2017) demonstrates that the development of smart and inclusive cities could be achieved by implementing a quadruple-helix model, which brings together four key factors: (1) the government, (2) corporate firms, (3) small and medium enterprises and (4) citizens.

(Kelley et al., 2016) conducted a study in which they showed that the main gaps related to innovative performances represent one of the causes of the differences between the levels of economic development.

Although it is obvious that technology plays a critical role in the development of smart cities, there are also some negative aspects of its use.

As (Odendaal, 2003) points out, an increase in the level of technology implemented in certain aspects of urban life can lead to an increase in inequality and digital divide.

We consider that an important aspect to be taken into account in the process of smart transformation of a city is the quality of the management, and in this sense (Marsal-Llacun et al., 2015) highlights the importance of permanent monitoring of smart city development initiatives, so that the transition from the classic to the smart city be a successful one, with the long-term beneficial effects. 
As we can see, at the level of literature there are several divergences regarding the optimal way for smart development of a city or a region, which is why we hope that through this work we will be able to bring arguments to support or refute these conclusions and to develop our own reasoned alternative related to smart and long-term sustainable development, an extremely important and current objective, both in Romania and in other countries of the world.

\section{Research Methodology}

To meet the established research objective, we used a diversified research methodology. In the first part of the paper we applied descriptive analysis, critical comparative analysis and statistical data to highlight the current stage of development of the four macro-regions of Romania, and also to see the level of our country compared to another developed country, Austria.

In the second part of the paper we tested the correlation between regional competitiveness and smart regions in order to see if the degree of competitiveness influences the degree of regions smartness. In this regard, we tested two hypotheses:

1. There is a positive and strong relationship between innovation and the position of countries in the competitiveness ranking;

2. There is a positive and strong relationship between the position of countries in the competitiveness ranking and the position of cities in the smart cities ranking.

To test the first hypothesis we used the following variables: the values of World Economic Forum (WEF) Global Competitiveness Index 4.0 (GCI) pillars and the overall WEF GCI values for each EU Member States.

Further, in order to test the second hypothesis, we calculated the correlation between Smart City Index 2019 - SCI (calculated by EasyPark Group) and WEF GCI. In the case of SCI 2019 we selected the most developed city in each EU Member Country that is in the ranking (most being capitals), and the data series that represents WEF GCI includes EU Member States whose cities are in the SCI 2019 ranking.

The correlations were determined using IBM SPSS Statistics software.

\section{The Current State of Smart Development of The Romania's Macroregions}

In this section we will try to determine the current level of smart development of the Romania's macroregions.

To achieve this objective, we will analyze their situation comparatively based on a series of relevant indicators, characteristics of four dimensions of smart cities, considered for this research, namely: smart economy, smart people, smart governance and smart digital infrastructure (Table 1).

Table 1. Indicators characteristic of the smart cities dimensions

\begin{tabular}{|c|c|}
\hline Smart City Dimension & Indicator \\
\hline Smart economy & Employment in technology and knowledge-intensive sectors \\
\hline Smart people & Percentage of population with tertiary education \\
\hline Smart governance & $\begin{array}{c}\text { Individuals who used the internet for interaction with public } \\
\text { authorities }\end{array}$ \\
\hline $\begin{array}{l}\text { Smart digital } \\
\text { infrastructure }\end{array}$ & Percentage of households with access to the internet at home \\
\hline
\end{tabular}


Source: made by authors based on (Giffinger et al., 2007).

At the same time, to see where our country stands compared to developed countries in the European Union (EU), we will compare the results obtained with those registered in Austria, by dividing it into development regions (Eastern Austria, Southern Austria and Western Austria).

We chose Austria as the reference country because it is one of the most competitive European countries and according to the "Smart City Strategy Index (SCSI) 2019" study, conducted by Roland Berger, which measures the complexity and initiatives of urban centers in terms of smart development, the capital of this country, Vienna, ranks first in the Top 153 states globally that have an official strategy for smart and sustainable development in the long-term.

The data used in this section are taken from Eurostat statistics and the analyzes are performed according to their availability.

The first dimension of a smart region / city that we will analyze is the smart economy.

In Figure 1 we give an overview of employment in technology and knowledge-intensive sectors.

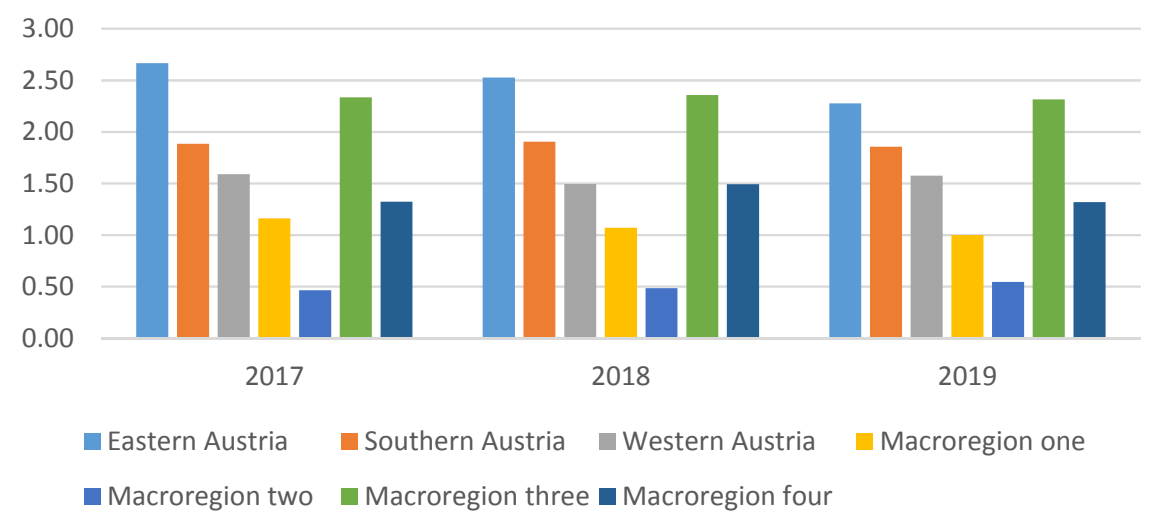

Fig. 1. The percentage of population employed in technology and knowledge-intensive sectors Source: made by authors based on Eurostat data Employment in technology and knowledge-intensive sectors by NUTS 1 regions and level of education (from 2008 onwards, NACE Rev. 2) [htec_emp_risced2]

The data in this graph shows that, during the entire analyzed period, the area of the country with the highest employment in technology and knowledge-intensive sectors is Macroregion three, which includes the capital Bucharest, while at the opposite side is Macroregion two. We can see that the gaps between the four macro is preserved during the entire analyzed period, which shows that no concrete measures are taken to attract investments for the development of technological and innovative industries in these areas.

Another important thing that emerges from this figure is that there are low gaps between the macroregions of Romania and those of Austria (exception Macroregion two), which indicates that our country is at a high level in terms of labor market specialization.

The second dimension characteristic of a smart region or city that we will analyze is smart people, and the chosen indicator is the percentage of active population with tertiary education (Figure 2). 


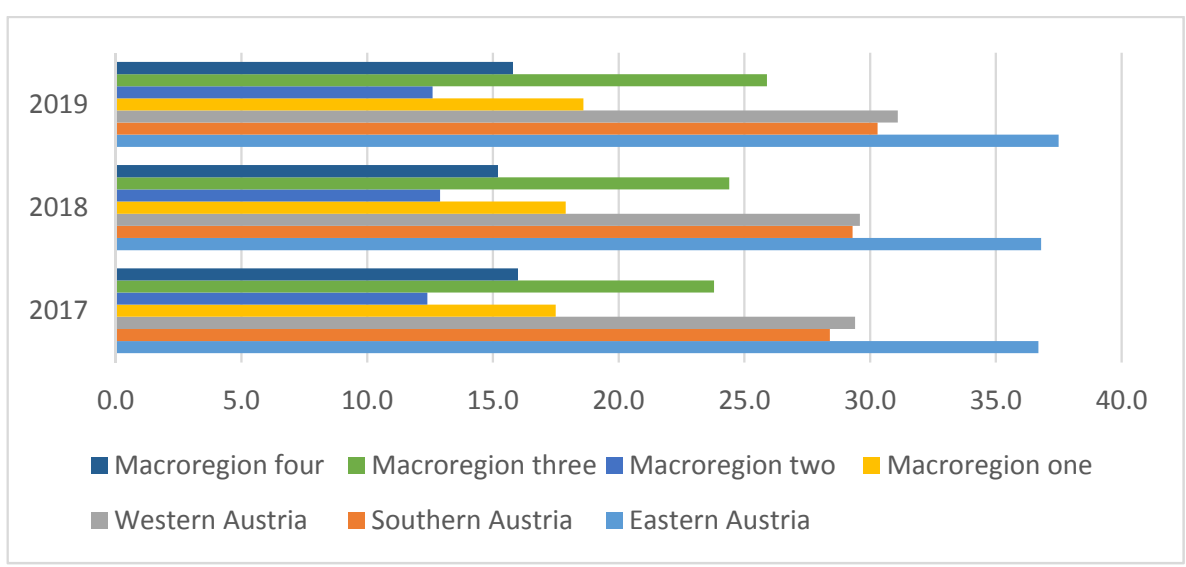

Fig. 2. Percentage of population aged 25-64 with tertiary education

Source: made by authors based on Eurostat data

Population aged 25-64 by educational attainment level, sex and NUTS 2 regions (\%) [edat_lfse_04]

The results presented in Figure 2 shows that in Romania the highest percentage of the population attending tertiary education is registered in Macroregion three, followed by Macroregions one, four and two. It should be noted that Macroregion three records the most consistent growth, slightly increasing the gap with the other macroregions. Compared to the situation recorded in Austria, our country is experiencing significant disparities.

This is closely related to the percentage of the population working in R\&D. Thus, the number of those who work in the R\&D field is influenced by the number of people who complete tertiary studies and remain to practice in Romania.

The third dimension specific to smart cities / regions is smart governance, and the indicator that we will use to quantify this dimension in the countries covered by this analysis is the percentage of individuals who used the internet for interaction with public authorities. Figure 3 presents the latest Eurostat data related to this indicator.

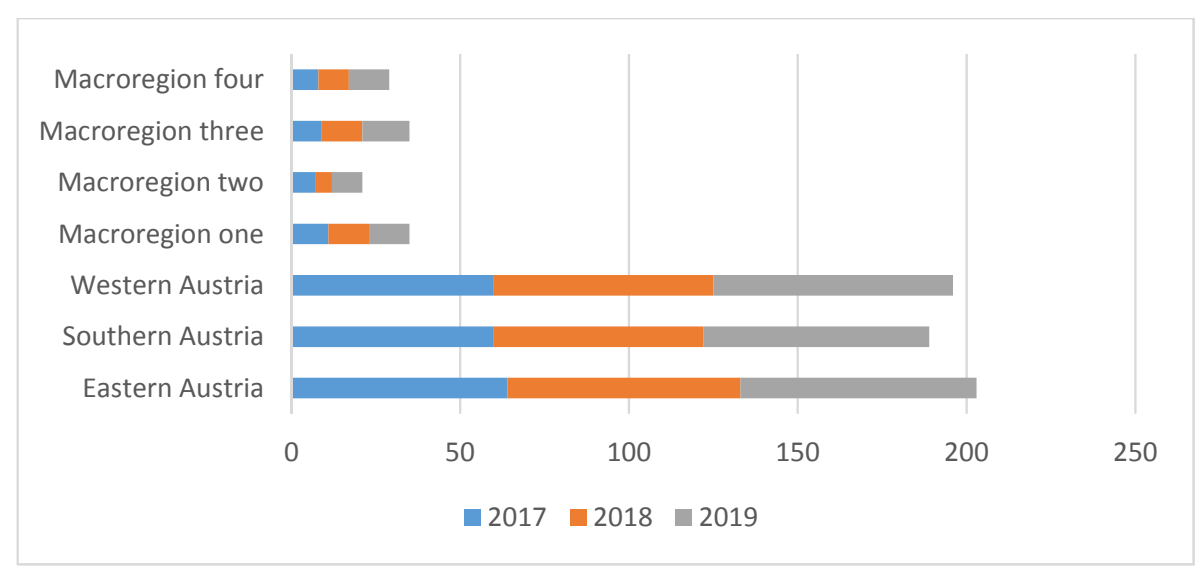

Fig. 3. Percentage of individuals who used the internet for interaction with public authorities Source: made by authors based on Eurostat data Individuals who used the internet for interaction with public authorities [isoc_r_gov_i]

The results shown in the figure above shows very low levels regarding e-government in Romania. The highest percentage (14\% in 2019) of our country's population interacting with public authorities through online channels is found in Macroregion three, followed by Macroregions one and four (12\% in 2019). 
Compared to the values registered in the regions of Austria, the differences are extremely large. For example, in 2019 the three macroregions registered about $70 \%$ percent in terms of population interacting with public authorities through e-government.

The governance problems in Romania are important, because they implicitly influence the level of competitiveness of the country. As we will see later in this research, according to "The Global Competitiveness Report 2019", the low performance of the public administration system (eg Government's responsiveness to change, Government long-term vision) is one of the main causes of low level competitiveness of our country.

The fourth dimension under analysis is smart digital infrastructure, and the indicator considered by us to be representative for this dimension is percentage of households with access to the internet at home (Figure 4).

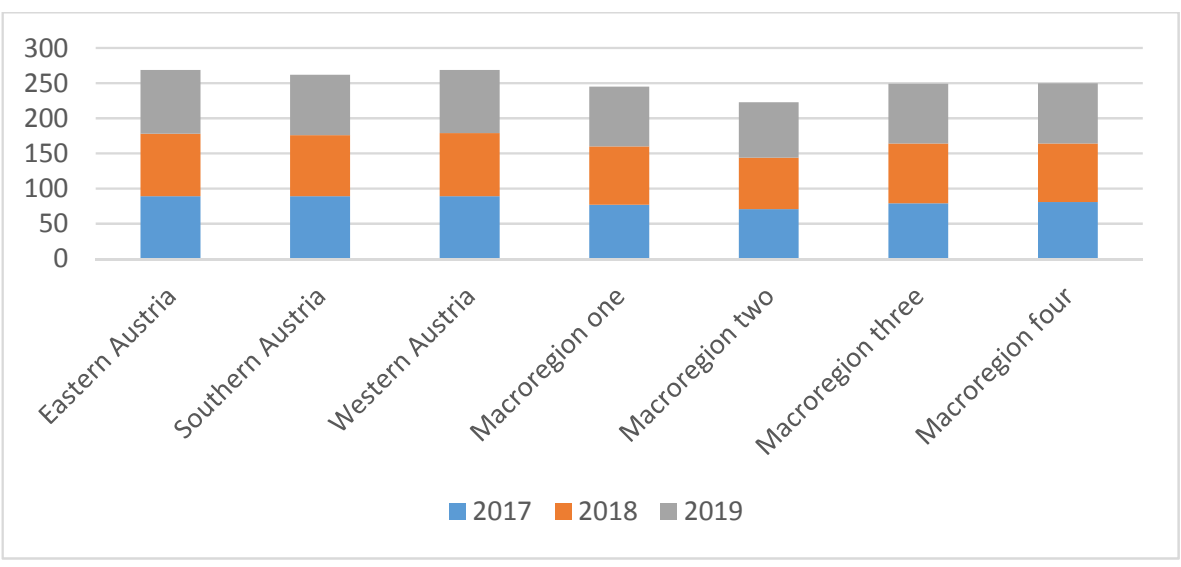

Fig. 4. Percentage of households with access to the internet at home

Source: made by authors based on Eurostat data

Households with access to the internet at home [isoc_r_iacc_h]

The results presented in Figure 4 shows that the percentage of households in Romania that have Internet access is high and approximately equal in the four macroregions. On the other hand, compared to the situation in Austria, we can see that the disparities between the macroregions of the two countries are low and tend to be equalized.

This proves that our country has the optimal digital infrastructure for smart development.

The analysis undertaken up to this point indicates high discrepancies between the macroregions of our country in terms of smart and sustainable development, the most obvious being from the point of view of the highly qualified human capital and smart governance, the best performances being registered by the Macroregion three. These differences are also reflected in the level of GDP / capita of the four national macroregions (Figure 5). 


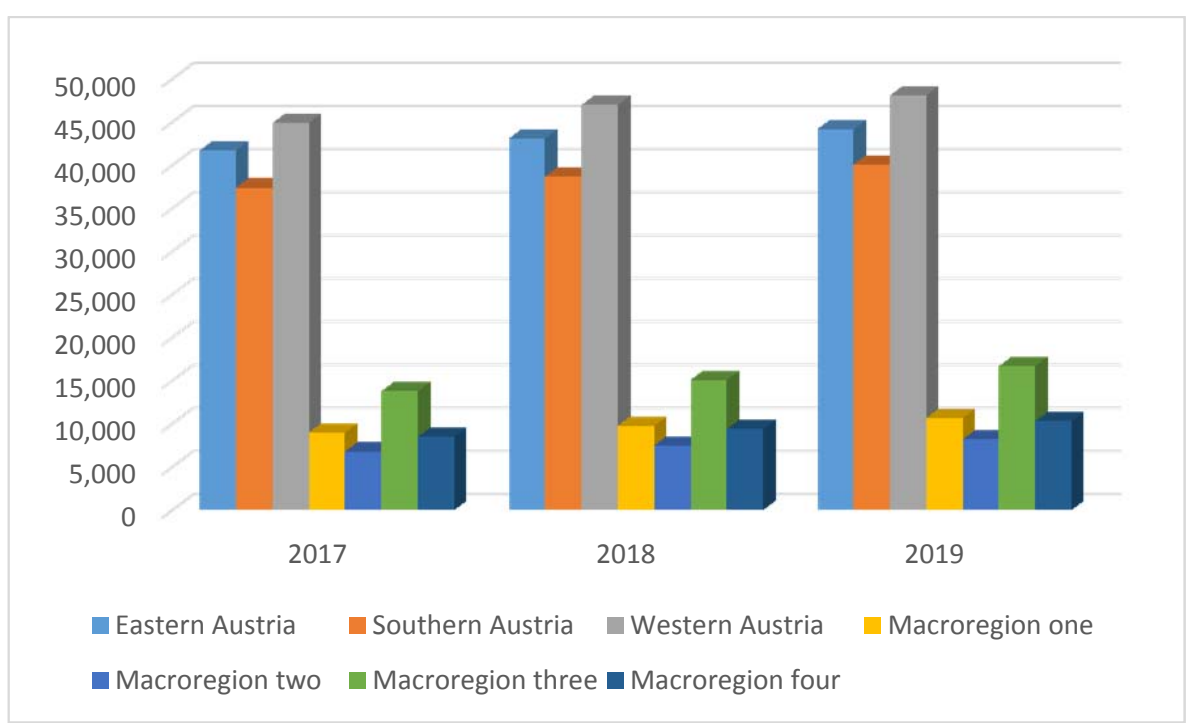

Fig. 5. GDP/capita of the Romania’s macroregions

Source: made by authors based on Eurostat data

Gross domestic product (GDP) at current market prices by NUTS 2 regions [nama_10r_2gdp]

The data presented in Figure 5 shows that the level of GDP / capita of Macroregion three it is almost double compared to the one recorded by the other three macroregions. and the differences between Romania and Austria are extremely large.

Our results so far show that, at least from the point of view of three of the smart cities / regions dimensions that we have analyzed in this section, our country register a low level of smart development, and in order for this situation to be improved, appropriate and sustainable measures are required.

Starting from these considerations, in the next section we will try to aggregate these scientific results and to test the general hypothesis according to which smart cities / regions develop in competitive areas.

\section{Sustainable and Smart Development Solutions. The Correlation between Regional Competitiveness and Smart Cities/Regions}

The indicators at which Romania shows gaps both inter-regionally and compared to developed countries in Europe (Austria), are sub-indicators of the competitiveness degree, as a result we start from the assumption that, in order to be sustainable and inclusive in the long run, the best measures to stimulate smart regional / urban development must focus mainly on increasing the degree of competitiveness. To verify our assumption, we will first test the two hypotheses set out in Section 1.

Hypothesis 1: There is a positive and strong relationship between innovation and the position of countries in the competitiveness ranking

As we have already stated, in order to verify the hypothesis stated above, we will test the connection between each of the Global Competitiveness Index 4.0 (GCI) pillars, calculated by the World Economic Forum (WEF), and the overall WEF GCI values for the member states of the European Union. The data refer to 2019.

The results of the correlations between the stated indicators are presented in Table 2 . 
Table 2. Bayesian correlations between WEF GCI pillars and WEF GCI, 2019

\begin{tabular}{|ll|c|c|c|c|} 
WEF GCI & \multicolumn{1}{|c}{ WEF GCI pillars } & Correlation & Count & Lower C.I. & Upper C.I. \\
\hline Dependent & Institutions &, 919 & 28 &, 830 &, 962 \\
\cline { 2 - 6 } & Infrastructure &, 805 & 28 &, 617 &, 906 \\
\cline { 2 - 6 } & ICT &, 478 & 28 &, 128 &, 722 \\
\cline { 2 - 6 } & Macroeconomic Stability &, 555 & 28 &, 230 &, 769 \\
\cline { 2 - 6 } & Health &, 503 & 28 &, 159 &, 737 \\
\cline { 2 - 6 } & Skills &, 850 & 28 &, 699 &, 929 \\
\cline { 2 - 6 } & Product Market &, 904 & 28 &, 800 &, 955 \\
\cline { 2 - 6 } & Labor Market &, 718 & 28 &, 471 &, 860 \\
\cline { 2 - 6 } & Financial System &, 925 & 28 &, 844 &, 965 \\
\cline { 2 - 6 } & Market Size &, 530 & 28 &, 195 &, 754 \\
\cline { 2 - 6 } & Business Dynamism &, 906 & 28 &, 806 &, 956 \\
\cline { 2 - 6 } & Innovation Capability &, 969 & 28 &, 933 &, 986 \\
\hline
\end{tabular}

Source: made by authors based on WEF The Global Competitiveness Report 2019 data.

The data in Table 2 shows that the dominant pillar of GCI is Innovation capability, which has the strongest correlation with overall GCI WEF. This confirms our hypothesis that the degree of innovation has a significant and positive influence on the level of countries competitiveness. Other pillars with a significant impact on the competitiveness are: the financial system, institutions, business dynamism, product market and skills.

It should be noted that ICT adoption plays a less important role in supporting the competitiveness of states, the correlation coefficient between this indicator and WEF GCI being the lowest (0.48).

Next, we will test the second hypothesis to see if innovation, as the main factor of competitiveness, has a significant impact on the level of smartness of a city.

Hypothesis 2: There is a positive and strong relationship between the position of countries in the competitiveness ranking and the position of cities in the smart cities ranking

Following the calculation of the correlation coefficient, the value of 0.87 resulted, which proves that there is a strong and positive connection between the two indicators, which confirms our second hypothesis.

Thus, the results obtained after testing the two hypotheses confirm the general hypothesis that smart cities are developing in competitive areas.

This conclusion is perfectly valid in the particular case of Romania: the low level of innovation contributes decisively to our country's position in the EU ranking of competitiveness, our country being on the $26^{\text {th }}$ place out of 28, and in the Smart City Index 2019 there is no city of Romania.

The corroborated results obtained in Section 3 and after testing the 2 hypotheses above demonstrate that the general hypothesis is also validated at the mezzo level.

Thus, we can consider that the low level of innovation of Romania's macroregions (NUTS 2), highlighted by low R\&D expenditures and a low number of personnel working in this field, leads to decreased competitiveness of these areas and implicitly to difficulties in smart and sustainable development.

The analysis of the level of competitiveness of our country, corroborated with the close connection it has with the degree of smart development, helps us to draw a number of other important conclusions, such as the fact that certain determinants of competitiveness (eg institutional framework, level of training) are at a low level in our country. Romania ranks $126^{\text {th }}$ in the world in terms of government policies stability, $108^{\text {th }}$ in terms of government's 
responsiveness to change, $113^{\text {th }}$ in terms of long-term government vision, and $72^{\text {nd }}$ in terms of skills. All these aspects again have a considerable negative impact on smart regional development.

Even if our country registers good results from the point of view of ICT adoption, we notice from this analysis that this indicator does not have a significant influence on competitiveness.

ICT is, however, an important pillar of smart development, but not enough, and cannot sustain long-term smart and sustainable development.

Based on all these results, the solution we propose for the smart, sustainable and inclusive longterm development of Romanian cities / regions is represented by increasing the level of competitiveness, especially through large investments in R\&D, highly qualified human capital, ensuring stability and developing the governmental framework and further supporting innovative entrepreneurship.

At the same time, we consider that the results obtained by us partially refute some of the studies presented in Section 2, at least for the specific case of Romania.

\section{Conclusions}

The present paper represents radiography of the present situation in Romania regarding the smart, sustainable and inclusive development in the long-term.

The first part of the paper showed that between the macroregions of Romania there are certain developmental gaps depending on several dimensions characteristic of the smart cities / regions considered by us, namely: smart governance, smart economy and smart people.

Another important conclusion is that Macroregion three has the highest performances in terms of smart development overall, which is closely related to the GDP / capita level.

Also, in this section of the paper we identified large gaps in our country compared to Austria, the country in the top "SCSI 2019" due to the official strategy for smart and sustainable longterm development.

The only area in which our country is maintained at a similar level with Austria is: households with access to the internet at home. However, even if we have a high number of people working in technology and knowledge-intensive sectors, the data on the personnel employed in research and development is low, which shows that the macroregions of our country are based on innovations from other countries.

In conjunction with these conclusions, in Section 3 we demonstrated that smart cities / regions are developing in competitive areas, and increasing competitiveness is the sustainable way of long-term smart development in Romania.

Thus, the main measures that we consider imperative are the increase of investments in innovation (R\&D), the support of the development of highly qualified human capital, the development of the government framework and the further stimulation of innovative and intelligent entrepreneurship.

As we stated at the beginning of this paper, we consider that this research is representative even for the most important cities in each macroregion of Romania, and in the future we want to test this hypothesis concretely and obtain relevant results that allows us to formulate specific solutions for the smart and sustainable development of each one. 


\section{References}

1. Apanaviciene, R., Vanagas, A., and Fokaides, P. A., 2020. Smart Building Integration into a Smart City (SBISC): Development of a New Evaluation Framework, Energies, 13(9), 2190.

2. Bakıcı, T., Almirall, E., Wareham, J., 2013. A smart city initiative: The case of Barcelona, J. Knowl. Econ., 4(2), 135-148.

3. Barney, J. B. and Clark, D. N., 2007. Resource-based theory: Creating and sustaining competitive advantage. Oxford: Oxford University Press.

4. EasyPark Group, 2020 Smart Cities Index 2019. Available through: https://www.easyparkgroup.com/smart-cities-index/ [Accessed: 21 April 2021].

5. Eurostat, 2020. Employment in technology and knowledge-intensive sectors by NUTS 1 regions and level of education (from 2008 onwards, NACE Rev. 2) [htec_emp_risced2]. Available through: http://appsso.eurostat.ec.europa.eu/nui/show.do?dataset=htec_emp_risced2\&lang=en [Accessed: 16 August 2021].

6. Eurostat, 2020. Households with access to the internet at home [isoc_r_iacc_h]. Available through: https://appsso.eurostat.ec.europa.eu/nui/show.do?dataset=isoc_r_iacc_h\&lang=en [Accessed: 16 August 2021].

7. Eurostat (2020) Individuals who used the internet for interaction with public authorities [isoc_r_gov_i]. Available at: http://appsso.eurostat.ec.europa.eu/nui/show.do?dataset=isoc_r_gov_i [Accessed: 16 August 2021].

8. Eurostat, 2020. Gross domestic product (GDP) at current market prices by NUTS 2 regions [nama_10r_2gdp]. Available at: http://appsso.eurostat.ec.europa.eu/nui/show.do?dataset=nama_10r_2gdp [Accessed: 16 August 2021].

9. Eurostat, 2020. Population aged 25-64 by educational attainment level, sex and NUTS 2 regions (\%) [edat_lfse_04]. Available through:

https://appsso.eurostat.ec.europa.eu/nui/show.do?dataset=edat_lfse_04\&lang=en [Accessed: 16 August 2021].

10. Fayomi, J. O. and Sani, Z. A., 2021. The future of work in the smart city: Managing virtual work by leveraging smart cities to achieve organizational strategy, Smart Cities and Regional Development (SCRD) Journal, Universul Academic Publishing House, 5(3), 103-114.

11. Florida, R., 2005. Cities and the Creative Class. Abingdon, UK: Routledge.

12. Giffinger, R., et al., 2007. Smart cities - Ranking of European medium-sized cities. Available through: http://www.smart-cities.eu [Accessed: 22 April 2021].

13. Guo, J., Ma, J., Li, X., Zhang, J. and Zhang, T., 2017. An attribute-based trust negotiation protocol for D2D communication in smart city balancing trust and privacy, Journal of Information Science and Engineering, 33(4), 1007-1023.

14. Kelley, D. J., Singer, S. and Herrington, M., 2016. The global entrepreneurship monitor. 2015-2016 Global Report. Available at: http://www.gemconsortium.org/report. [Accessed: 21 April 2021].

15. Kummitha, R.K.R. and Crutzen, N., 2017. How do we understand smart cities? An evolutionary perspective, Cities, 67, 43-52.

16. Lom, M., Pribyl, O. and Svitek, M., 2016. Industry 4.0 as a part of smart cities, 2016 Smart Cities Symposium Prague (SCSP), Prague, Czech Republic, 26-27 May 2016.

17. Marsal-Llacuna, M. L., Colomer-Llinàs, J. and Meléndez-Frigola, J., 2015. Lessons in urban monitoring taken from sustainable and livable cities to better address the smart cities initiative, Technological Forecasting and Social Change, 90(PB), 611-622.

18. Odendaal, N., 2003. Information and communication technology and local governance: Understanding the difference between cities in developed and emerging economies, Computers, Environment and Urban Systems, 27(6), 585-607.

19. Ortiz-Fournier, L. V., et al. 2010. Integrating educational institutions to produce intellectual capital for sustainability in Caguas, Puerto Rico, Knowledge Management Research and Practice, 8(3), 203-215.

20. Roland Berger, 2019. Think: Act. The Smart City Breakaway. Available through: https://www.rolandberger.com/publications/publication_pdf/roland_berger_smart_city_breakaway_ 1.pdf [Accessed: 20 April 2021].

21. Romanelli, M., 2021. Rediscovering urban intelligence within cities by technologies, Smart Cities and Regional Development (SCRD) Journal, 5(3), 115-122. 
22. Szabo, Z. K. and Herman, E., 2014. Productive entrepreneurship in the EU and its barriers in transition economies: A cluster analysis, Acta Polytechnica Hungarica, 11(6), 73-94.

23. World Economic Forum, 2020. The Global Competitiveness Report 2019. Available through: http://www3.weforum.org/docs/WEF_TheGlobalCompetitivenessReport2019.pdf (Accessed: 23 April 2021).

24. World Bank, 2019. World Development Report 2019: The Changing Nature of Work. Washington. Available through: https://www.worldbank.org/en/publication/wdr2019 (Accessed: 20 April 2021). 